\title{
Meaningful Consideration? A Review of Traditional Knowledge in Environmental Decision Making
}

\author{
STEPHEN C. ELLIS ${ }^{1}$
}

(Received 19 December 2003; accepted in revised form 28 July 2004)

\begin{abstract}
In Canada's Northwest Territories, governments, industrial corporations, and other organizations have tried many strategies to promote the meaningful consideration of traditional knowledge in environmental decision making, acknowledging that such consideration can foster more socially egalitarian and environmentally sustainable relationships between human societies and Nature. These initiatives have taken the form of both "top-down" strategies (preparing environmental governance authorities to receive traditional knowledge) and "bottom-up" strategies (fostering the capacity of aboriginal people to bring traditional knowledge to bear in environmental decision making). Unfortunately, most of these strategies have had only marginally beneficial effects, primarily because they failed to overcome certain significant barriers. These include communication barriers, arising from the different languages and styles of expression used by traditional knowledge holders; conceptual barriers, stemming from the organizations' difficulties in comprehending the values, practices, and context underlying traditional knowledge; and political barriers, resulting from an unwillingness to acknowledge traditional-knowledge messages that may conflict with the agendas of government or industry. Still other barriers emanate from the co-opting of traditional knowledge by non-aboriginal researchers and their institutions. These barriers help maintain a power imbalance between the practitioners of science and European-style environmental governance and the aboriginal people and their traditional knowledge. This imbalance fosters the rejection of traditional knowledge or its transformation and assimilation into Euro-Canadian ways of knowing and doing.
\end{abstract}

Key words: traditional knowledge, environment, aboriginal, governance, power, Northwest Territories, policy, management

RÉSUMÉ. Dans les Territoires du Nord-Ouest du Canada, les gouvernements, les sociétés industrielles et autres organisations ont essayé de nombreuses stratégies pour promouvoir une prise en considération sérieuse du savoir traditionnel dans le processus décisionnel visant l'environnement, reconnaissant qu'une telle prise en considération peut favoriser des relations plus égalitaires sur le plan social et plus durables sur le plan écologique entre les sociétés humaines et la Nature. Ces initiatives ont pris la forme de stratégies «descendantes» (préparant les autorités de gouvernance environnementale à accepter le savoir traditionnel) et de stratégies «ascendantes» (favorisant la capacité des Autochtones à peser sur la prise de décisions visant l'environnement). Malheureusement, la plupart de ces stratégies n'ont eu que des effets bénéfiques marginaux, en raison surtout de leur échec à surmonter certains obstacles cruciaux, dont les entraves à la communication, nées de la diversité des langues et styles d'expression propres aux détenteurs de savoir traditionnel; les obstacles d'ordre conceptuel, issus des difficultés qu' ont les organisations à saisir les valeurs, les pratiques et le contexte sous-jacents au savoir traditionnel; et les obstacles politiques, découlant du manque de volonté à reconnaître les messages du savoir traditionnel qui pourraient être incompatibles avec les plans du gouvernement ou de l'industrie. Il y a aussi d'autres obstacles émanant de la cooptation du savoir traditionnel par les chercheurs non autochtones et leurs institutions. Ces barrières contribuent à maintenir un déséquilibre de pouvoirs entre, d'un côté, les adeptes de la science et de la gouvernance environnementale de style européen, et de l'autre, les Autochtones et leur savoir traditionnel. Ce déséquilibre favorise le rejet du savoir traditionnel ou sa transformation et assimilation à la façon d'apprendre et de faire euro-canadienne.

Mots clés: savoir traditionnel, environnement, autochtone, gouvernance, pouvoir, Territoires du Nord-Ouest, politique, gestion

Traduit pour la revue Arctic par Nésida Loyer.

\section{INTRODUCTION}

Traditional knowledge, broadly defined as a cumulative, collective body of knowledge, experience, and values held by societies with a history of subsistence (Zamparo, 1996; Huntington, 1998; Berkes et al., 2000), has been prominent in the discourse surrounding land and resource management and decision making for about 20 years. Because of its acknowledged connection with environmental sustainability and the empowerment of marginalized peoples, it has been variously analyzed, systemized, and incorporated into a myriad of environmental decisionmaking processes. These include environmental assessment (Stevenson, 1996; Wiles et al., 1999), land-claim and treaty entitlement processes (Freeman, 1976; Teed, 2002), wildlife management (Usher, 1987; Gunn et al., 1988),

\footnotetext{
${ }^{1}$ Łutsël K'é, Northwest Territories X0E 1A0, Canada; present address: 3428 State Hwy 14N, Cerrillos, New Mexico 87010, U.S.A.; stevecellis@yahoo.com

(C) The Arctic Institute of North America
} 
and land-use regulation (Duerden and Kuhn, 1998). A variety of strategies have been used in an attempt to bring traditional knowledge into these processes. Questions remain, however, concerning the success of these diverse approaches.

Impetus for the incorporation of traditional knowledge into environmental decision making comes from two sources. Firstly, some western theorists, researchers, and aboriginal peoples perceive traditional knowledge to be a means of informing sustainable living and environmental management practices (Sillitoe, 1998; Berkes et al., 2000; Agrawal, 2002). By employing traditional knowledge, it is thought, a greater breadth and depth of environmental information can be brought to bear, along with a more holistic understanding of the relationships amongst living beings and their environments (Huntington, 2000). It is proposed that traditional knowledge, either on its own or in conjunction with science, can greatly aid in predicting and preventing the potential environmental impacts of development, as well as informing wise land-use and resource management. Proponents of traditional knowledge maintain that it can offer contributions to environmental decision making from a broader scope of environmental values, practices, and knowledge.

Secondly, aboriginal groups have supported and promoted discussion around traditional knowledge in the interest of aboriginal empowerment (Legat, 1991; Martinez, 1994; Agrawal, 2002). Environmental decision making has historically been the domain of government bureaucrats and managers trained in the scientific tradition, who may have little understanding of the cultural context in which aboriginal people live. With the advent of increased self-determination in many regions (e.g., land claims, treaty entitlement settlements), aboriginal people are seeking to increase their role in environmental decision making, particularly as it directly concerns their traditional lands (Purcell and Onjoro, 2002). By promoting the recognition and use of their traditional knowledge in environmental governance, aboriginal people necessarily advocate an increased role for the holders of traditional knowledge. The theory is that an increase in role will empower aboriginal people (Legat, 1991). Aboriginal people will have a greater capacity to contribute to, and thus exert control over, decisions pertaining to their traditional lands.

The Northwest Territories (NWT) of Canada serve as a good forum for an examination and evaluation of strategies and techniques that have been, and continue to be, employed to bring traditional knowledge into environmental decision making. The promotion of traditional knowledge in environmental decision making has been particularly prominent in the NWT, where aboriginal people form a majority of the population and maintain close relationships with their traditional lands. Aboriginal organizations in the NWT, as well as certain Euro-Canadian theorists and researchers, have applied significant pressure upon government and industry in an effort to ensure that traditional knowledge is incorporated into NWT environmental decision-making processes. In response, federal and territorial government departments and industrial corporations with environmental interests, in their policies, have officially recognized the importance of traditional knowledge. They have also initiated programs and procedures with the express purpose of introducing traditional knowledge into their environmental decisionmaking processes (GNWT, 1993; BHPB, 2001; De Beers Canada Mining Inc., 2002; INAC, 2003).

This paper reviews strategies for bringing traditional knowledge into environmental decision-making processes, focusing on the case of the NWT. It describes government, industry, and other organizational strategies for linking traditional knowledge and environmental governance and critiques them, drawing upon my own and others' experiences with such strategies during their implementation. This critique will assess the strategies in light of the two instrumental purposes of promoting traditional knowledge in environmental decision making: a) ensuring that traditional knowledge has a real influence on environmental decision making, and b) empowering aboriginal people in environmental governance processes. It will identify and explore successes and deficiencies evident in the strategies with regard to realizing these two goals, and in the case of deficiencies, will consider the beginnings of solutions.

\section{THE APPLICATION OF TRADITIONAL KNOWLEDGE}

Practical methods for encouraging the use of traditional knowledge in environmental decision-making processes generally fall into two archetypical categories. The first category includes those methods that are based on the official recognition of traditional knowledge, followed by the development of rules of procedure for the use of this knowledge by institutions of authority. In this "top-down" approach, the structures of governance are constructed to accommodate traditional knowledge, but the knowledge itself is not fostered or sought out. The second category increases the capacity of aboriginal people to bring traditional knowledge to bear on policies and procedures of governance and regulation. This "bottom-up" approach is characterized by initiatives designed to encourage the learning and transmission of traditional knowledge at the community level, as well as developing the means to communicate this knowledge within the structures and processes of environmental governance.

These methodological approaches are not mutually exclusive, and indeed need to be considered in concert if the use of traditional knowledge in environmental decision making is to be fostered successfully. Creating policies and procedures for the inclusion of traditional knowledge in institutions of authority is a fruitless endeavour if aboriginal groups do not have the capacity to develop or transmit their knowledge. Likewise, promoting the capacity to develop and transmit traditional knowledge in the interest of decision making is largely ineffective if the 
structures of governance are not prepared to receive this type of knowledge. The agents of government and industry in the NWT have implemented these two approaches in various policies, programs, and procedures.

\section{The Top-Down Approach}

The top-down approach is employed primarily by those agencies with the power to regulate and legislate. Indian and Northern Affairs Canada (INAC), the federal department with legislative and policy authority over Crown land and natural resources in the NWT, ultimately regulates and administers most resource-development activities. According to the department's principles for sustainable development, INAC must exercise its authority in a way that maintains respect for diverse cultures and traditional values and provides fair and equitable opportunities for aboriginal peoples. Decisions must be based on the best available scientific, traditional, and local knowledge (INAC, 2003). INAC is responsible for developing and implementing the great majority of the top-down initiatives meant to foster the inclusion of traditional knowledge in the regulation of land and water use in the NWT.

The most evident of these initiatives has been the overhauling of the regulatory process through the settlement of land claims and the Mackenzie Valley Resource Management Act (MVRMA). Responsibility for reviewing and approving land-use permit and water licence applications in the NWT lies with regional co-management boards and two pan-territorial co-management boards: the Mackenzie Valley Land and Water Board (MVLWB) and the Mackenzie Valley Environmental Impact Review Board (MVEIRB). Land and water use applications are reviewed following procedures that are unique in Canada.

Resource development proponents submit applications for land-use permits and water licences to the MVLWB. The board then distributes these applications to all potentially affected aboriginal groups, typically, aboriginal groups with communities or traditional land-use interests near the proposed development. This is the "pre-screening" process (MVEIRB, 2003), which typically gives aboriginal groups 30 to 45 days to provide comments and recommendations to the board concerning the proposed development. Once the time for pre-screening has elapsed, the board reviews the applications, consults with technical experts, and either approves or rejects the applications on the basis of their economic and environmental merits. Sometimes hearings are held to seek public input into a review: this typically occurs when a proposed project is deemed to be of significance to the general populace. Finally, the Minister of INAC, whose department has the ultimate authority on land and resource use, must sign off all decisions made by the board. Once granted ministerial approval, proponents receive the relevant permits and licences for their proposed development, often with attached conditions and restrictions as determined by the board.
Sometimes, if a proposed project is deemed likely to have significant adverse effects on the environment, the MVLWB recommends it to the MVEIRB for an environmental assessment. Aboriginal groups are able to declare themselves as interveners in an environmental assessment and can thus participate in a number of processes, including the development of terms of reference, a conformity check of the proponent's environmental assessment report, a formal information request period, technical sessions, and public hearings. If the MVEIRB is satisfied that a proposed development will have minimal negative environmental impact, it is then referred back to the MVLWB for the issuance of permits and licences, usually with recommendations for terms and conditions of approval (MVEIRB, 2003).

The MVRMA regulatory process purports to consider traditional knowledge in three primary ways. Firstly, aboriginal groups potentially affected by a proposed development can make recommendations substantiated by traditional knowledge through the pre-screening process or as interveners. Secondly, aboriginal representatives comprise half the members of the MVLWB and the MVEIRB. These representatives can evaluate and review a proposed project using the values, information, and experience that stem from the traditional knowledge of their people. Thirdly, aboriginal groups are able to make statements and presentations at technical sessions and public hearings. In all these processes, ostensibly, concerns and recommendations stemming from traditional knowledge are considered fully and equally with those based on science.

The Government of the Northwest Territories (GNWT) has also taken the top-down approach to encourage the use of traditional knowledge in environmental decision making. While the territorial government has little jurisdiction over land and resources in the NWT compared to the federal government, it does exercise regulatory power over permits for wildlife research and exploitation. According to the GNWT policy on traditional knowledge, the territorial government "recognizes that aboriginal traditional knowledge is a valid and essential source of information about the natural environment and its resources, the use of natural resources, and the relationship of people to the land and to each other, and will incorporate traditional knowledge into government decisions and action where appropriate" (GNWT, 1993). In applying this policy to the review of wildlife research permits, the GNWT requires applicants to consult with the appropriate authorities in aboriginal communities near the proposed study area. In order to be positively considered for a wildlife research permit, applicants must provide a recommendation form signed by the appropriate aboriginal authorities (GNWT, 2003). In theory, aboriginal groups have the discretion to apply their traditional knowledge in deciding whether to provide a recommendation to the GNWT concerning a particular research permit.

Industrial corporations have also implemented topdown approaches to fostering traditional knowledge in 
environmental decision making. Diavik Diamond Mines Inc., as a requirement of its environmental agreement (a legal instrument currently required of the diamond industry in the NWT), has adopted a top-down approach to promoting traditional knowledge in its management of environment issues. Diavik has established an Environmental Monitoring Advisory Board (EMAB) composed of representatives from the federal and territorial governments, Diavik, and aboriginal communities affected by the mine development. This board is responsible for, among other things, the provision of meaningful roles for aboriginal people in the monitoring, management, and regulation of the Diavik mine. Aboriginal members of the EMAB can make recommendations based upon their traditional knowledge to regulatory authorities and to the mining company, advocate for traditional knowledge studies relevant to the mine, and generally serve as the voice of their people (DDMI, 2001). Diavik has built a structure whereby traditional knowledge can theoretically gain entry into the decision-making process.

Another top-down approach employed by industry is exemplified in the preparation of the environmental assessment report for the Snap Lake Diamond Project. De Beers Canada Mining Inc., the project proponent, has been navigating the environmental assessment process in the hopes of receiving the land-use permits and water licence necessary for mine production. The terms of reference for this report state that "Traditional knowledge shall be given full and equal consideration to that of western science." To do this, De Beers constructed a framework for the incorporation of traditional knowledge into its environmental assessment report. This framework established that traditional knowledge was to be used by De Beers to identify or confirm valued ecosystem components and environmental issues in the Snap Lake area, identify alternative project designs, and develop mitigation measures for environmental impacts (De Beers Canada Mining Inc., 2002).

\section{The Bottom-Up Approach}

The top-down approach to the incorporation of traditional knowledge into environmental governance described above is of little use if traditional knowledge cannot be accessed and is not forthcoming. Many organizations thus employ a bottom-up approach to increase the capacity of aboriginal people to bring traditional knowledge to bear on policies and procedures of governance. In the NWT, this approach has largely been a development exercise with two primary thrusts: the first seeks to increase aboriginal groups' means to participate in environmental decision making, while the second strives to maintain, cultivate, and indirectly promote traditional knowledge in the communities. The first thrust is typically implemented by the provision of funds to aboriginal groups to participate in environmental decision-making processes, such as public hearings and environmental assessments. The federal and territorial governments have been the primary agencies providing resources to aboriginal groups for this purpose, through such initiatives as the Interim Resource Management Assistance program and the Environmental Capacity Development Initiative, as well as through funds to support local Lands and Environment Committee activities. These types of funding programs do not specifically serve to increase the capacity of aboriginal people to bring traditional knowledge into environmental decision making. However, the theory is that increasing the general capacity of aboriginal groups to participate in these processes will naturally promote traditional knowledge.

The second thrust of the bottom-up approach seeks to foster traditional knowledge at the community level. This thrust does not promote the use of traditional knowledge in environmental decision-making processes directly, but rather indirectly, by seeking to ensure that traditional knowledge is available for such purposes. Aboriginal people in the NWT are keenly aware that, if their traditional knowledge is not used, documented, or otherwise encouraged, it will soon become an artifact of the past. Elders are passing away, and much of their knowledge is not being transmitted to younger generations (Gwich'in Elders and Raydorogetsky, 1997). This second thrust seeks to conserve and promote existing traditional knowledge, as well as to cultivate socio-cultural initiatives that ensure it will be passed on and continue to evolve. Aboriginal groups are using resources accessed through governments, industry, and research organizations for this purpose.

In a statement to the Legislative Assembly of the GNWT, the Honourable Jim Antoine said that the Department of Resources, Wildlife and Economic Development "has embarked on a process designed to rebuild capacity in the traditional economy. Training programs targeting youth...have been developed to teach trapping and traditional life skills" (Antoine, 2002). Programs such as the Community Harvester Assistance Program and the Western Harvesters Assistance Program provide subsidies to aboriginal land users to help them purchase the equipment and supplies they need to engage in traditional harvesting activities. Such subsidies help ensure that traditional knowledge is continually being updated through people's experiences on the land. Other programs provide funding for on-the-land activities, such as elder-youth camps, and cultural activities, such as hunting trips and spiritual gatherings.

As a condition of its environmental agreement with the federal and territorial governments, BHP Billiton Diamonds Inc. (BHPB) was required to "...incorporate all available traditional knowledge in the Environmental Plans and Programs..." and "...give all available traditional knowledge full consideration along with scientific knowledge..." (IEMA, 2001). BHPB thus provides resources to aboriginal organizations for traditional knowledge studies, particularly traditional land-use mapping based on Geographic Information Systems. De Beers Canada Mining Inc., prompted by similar requirements in the terms of reference for environmental assessment of its Snap Lake Diamond Project, provided funding for a comprehensive 
elders' assessment of the proposed mining project ( $\mathrm{K}$ KDFN and Ellis, 2002; De Beers Canada Mining Inc., 2002).

One goal of research initiatives such as the West Kitikmeot Slave Study is to generate and document traditional knowledge for use in environmental decision making (WKSS, 2001). These initiatives encourage aboriginal groups to map traditional land use and record oral histories, legends, myths, and knowledge about the wildlife, plants, and geography in their traditional territories. Such studies typically employ local aboriginal people versed in their native language to conduct interviews and record the stories of elders and other land users on a variety of topics, from traditional ways of living to the biology and behaviour of specific animal species. Two examples are the Traditional Ecological Knowledge in the Kache Tué Study Region project ( $\mathrm{KKDFN}$ et al., 2001) and the Dogrib Traditional Knowledge Project (Dogrib Treaty 11 Council, 2001).

While by no means a complete enumeration, the previous examples from the NWT provide an overview of the types of policies, programs, and procedures used to promote the consideration of traditional knowledge in environmental decision making. Together, the top-down and bottom-up approaches have as ultimate objectives the use of traditional knowledge to influence environmental decision making and the empowerment of aboriginal people in environmental governance. But how effective have they been at accomplishing these objectives?

\section{A CRITIQUE OF TRADITIONAL KNOWLEDGE IN PRACTICE}

The critique begins by specifically considering traditional knowledge policies in the NWT. As Paci et al. (2002) and Usher (2000) effectively demonstrate, these policies, while well-intentioned and comparatively progressive, consistently lack either direction or common agreement on what traditional knowledge is, what kind of information it provides, and how it can be accessed and brought into environmental governance processes. Traditional knowledge policy requirements provide virtually no guidance for implementation. As a result, organizations are left to interpret and implement these policies as they see fit.

In fact, policy actualization is typically left up to aboriginal participants. Many agencies perceive the participation of aboriginal people in environmental governance processes as constituting consideration of traditional knowledge (Duerden and Kuhn, 1998). It is fairly assumed that aboriginal people understand the nature and utility of traditional knowledge and thus are best suited to bring this knowledge into environmental decision making. Consequently, aboriginal participants in environmental governance processes are frequently expected to bring forward traditional knowledge and interpret it in the context of discussion at hand (Barnaby et al., 2003b).
The incorporation of traditional knowledge into environmental decision making, however, is not an automatic result of aboriginal participation in these processes. This is because the structures and procedures of environmental governance are very much entrenched in the Euro-Canadian cultural tradition of decision making, even though they allow for aboriginal people to participate within the confines of this tradition (Cizek, 1990; Kuhn et al., 1994; Simpson, 2001). Environmental governance in the NWT is typically discussed at meetings and workshops organized by boards and committees. Language in these meetings and workshops can be rife with technical and scientific terms (Bielawski, 2003; MVEIRB, 2004). Such discussions, based on written documents and correspondence in English, have few analogues within cultures immersed in traditional knowledge, where oral communication in native languages is the norm. The decisions they produce are often based upon Euro-Canadian value systems and scientific evidence, whereas in traditional-knowledge cultures, they are often based on experience (Goulet, 1998). Consequently, traditional knowledge experts (often elders) rarely have much understanding of environmental decision-making procedures, let alone the material discussed as evidence in meetings and workshops, which limits their ability to contribute meaningfully. To illustrate, Kruse et al. (1998) provide evidence that aboriginal representatives on co-management boards do not report the outcomes from meetings back to their communities because they lack understanding about what was discussed.

\section{The Specialization of Environmental Decision Making}

Environmental governance in the NWT is embedded in the Euro-Canadian traditions of science and decision making, inclining aboriginal governments to designate individuals versed in these concepts and methods to be their representatives in environmental discussion. Aboriginal people who have gone to college and who thus may comprehend the conventional discourse surrounding environmental governance are often appointed to such roles. However, even people with a Western higher education may have difficulties. Environmental governance discussions are usually very specialized in nature, requiring expertise in such fields as biology, hydrology, geology, law, and engineering. An individual must have expertise and experience in such technical disciplines to comprehend and meaningfully participate in environmental decision-making discussions. Aboriginal people with such specialization are rare in the NWT. When interviewed, eight aboriginal leaders from across the NWT stated that it is often difficult to find people who are recognized as having traditional knowledge and are also technically able to participate in environmental governance processes (Barnaby et al., 2003b).

As a result, aboriginal governments often hire non-aboriginal scientific experts to represent them in processes of environmental governance, particularly in the typically very 
specialized public hearings and technical sessions. Bielawski (2003) noticed this trend in 1996 while participating in public hearings concerning BHP Billiton Diamonds Inc.'s application for a water licence, and it was echoed at public hearings held in 2003 for the environmental assessment of the Snap Lake Diamond Project (MVEIRB, 2003). The majority of such scientific experts have an extremely limited capacity to contribute traditional knowledge to environmental decisionmaking processes.

This is not to suggest that aboriginal groups employ only non-aboriginal scientific experts as their representatives in environmental governance processes. For example, the Łutsël K'é Dene First Nation was predominantly represented by community elders at the public hearings for the Snap Lake Diamond Project (MVEIRB, 2003). Some aboriginal organizations will still attempt to incorporate their traditional knowledge into these processes by designating elders and other land users as their representatives in public hearings and technical sessions. However, the effective transmission of traditional knowledge in these forums remains very challenging.

\section{The Importance of Language and Translation}

Initial challenges simply have to do with language. Most elders and other traditional knowledge experts are comfortable only when communicating orally in their native languages (Colorado, 1988). As a result, most traditional knowledge experts can participate in environmental governance discussions only through interpreters. These interpreters, in the NWT, are commonly aboriginal professionals who are versed in both English and a native language. They must understand the highly technical discussions of science and then translate them understandably into aboriginal languages. To be completely effective, an interpreter must first be familiar with relevant technical fields in order to understand scientific terms and concepts such as "eutrophication" and "watershed management." This is possible only if the interpreter has had considerable and often quite specific training in the range of relevant technical fields. Interpreters also need both a sophisticated understanding of the traditional language and training in interpretation. The latter is a highly specialized skill requiring substantial education. Such a combination is understandably rare.

The above problem is compounded by the fact that aboriginal languages have no words for such scientific concepts as "eutrophication" and "watershed management." Even if an interpreter understands these terms, translating them for traditional knowledge experts is extremely difficult, if not impossible (Legat, 1991; Martinez, 1994). In one telling episode during public hearings for a proposed expansion of the Ekati Diamond mine, the proponent's technical experts gave a presentation concerning levels of ammonia in mine water effluent (MVLWB, 2002). There being no equivalent word for or description of ammonia in aboriginal languages, interpreters simply inserted the word "ammonia" into their translations when referring to the chemical in question. After the hearing, one of the interpreters (B. Catholique, pers. comm. 2002) explained that the elders were quite confused during this presentation, as they understood the mine water effluent to be "infected with pneumonia."

These challenges mean that traditional knowledge experts often receive translations during environmental decision-making discussions that are oversimplified or even incorrect. Nonetheless, they are expected to contribute meaningfully to environmental governance proceedings on the basis of these translations. Interpreters are then faced with the challenge of communicating the statements of traditional knowledge experts to an English-speaking audience. To do so, they must have a sophisticated understanding of traditional knowledge and be able to communicate this knowledge effectively to those unfamiliar with its nuances and concepts. They must also transmit the meaning of terms and concepts that are unique to the relevant aboriginal language. Thus it is often the case that the contributions of traditional knowledge experts heard by government or industry representatives are perceived as simplistic or even incomprehensible (Barnaby et al., 2003b). The dialogue between science and traditional knowledge is so hampered by fundamental differences in concept and language that effective communication becomes extremely difficult (Goulet, 1998).

\section{The Role of Metaphor}

Even when traditional knowledge is effectively transmitted through superb oratory and translation efforts, participants in environmental decision-making processes may have difficulties comprehending this knowledge (just as traditional knowledge experts have trouble understanding scientific communications). Traditional knowledge statements can be difficult to interpret and confusing for those not familiar with aboriginal styles of communication. They are often communicated in ways that are foreign to conventional scientific style, using metaphor, analogy, and myth to transmit cultural values or information. Petitot (1976) and Blondin (1990) documented many such communications in the form of stories from various aboriginal peoples in the NWT.

Traditional knowledge experts draw from a broad range of knowledge and experience when communicating. Environmental knowledge, cultural values, history, politics, and the broad concerns and aspirations of their people may often inform the speech of an elder or other land user participating in an environmental hearing or technical session. Such speakers rarely limit themselves to a specific topic, but rather provide holistic analyses and broad statements (Snowshoe, 1977; Roue and Nakashima, 2002). An account by elder Morris Lockhart in a public hearing concerning an expansion of the Ekati Diamond Mine (MVLWB, 2002) covered many subjects, including his personal history, aboriginal identity and values, the colonial 
experience, and previous industrial developments and their impacts upon his people and the land. He effectively outlined the values and concerns of his people around the proposed expansion in terms of his people's traditional knowledge and experiences. Not once, however, did he even mention the particular development with which the hearing was concerned. Consequently, much of his message was lost on some of the government and industry representatives at the hearing. A few questioned the relevance of the elder's statement, commenting aloud that the development in question was not addressed. Others, who understood its relevance and listened with interest, may still have been at a loss, as there was a complete absence of questions after the elder's presentation. Bielawski (2003) noticed the same difficulty in dealing with elders' comments during the regulatory process surrounding the initial Ekati Diamond Mine hearings in 1996, as did Nadasdy (1999) during resource co-management meetings.

\section{The Scientization of Traditional Knowledge}

This brings us to another fundamental problem with the top-down approach. Notions outside the realm of science and Euro-Canadian values are often considered unworthy of serious discussion in environmental decision-making processes (Colorado, 1988). Traditional knowledge is often seen as legitimate only when it has been adapted to the specialized narrative of science (Mauro and Hardison, 2000; Simpson, 2001; Agrawal, 2002; Raffles, 2002). Traditional knowledge perceived as directly relevant to conventional environmental governance is most often incorporated into the decision-making process. However, knowledge that may seem to be irrelevant to the task of Western-style environmental decision making, like the statements of Morris Lockhart at the Ekati expansion public hearing, is commonly ignored.

The step whereby knowledge deemed amenable to environmental decision making is separated from other knowledge is the first in a process that Agrawal (2002) describes as "scientization," which involves distinguishing the descriptive from the analytic, the anecdotal from the systematic, and the mythic from the factual (Raffles, 2002). The second step in this process involves testing and validating relevant knowledge using scientific criteria. The criteria most often applied are replicability, rationality, rigour, and universality. Direct, empirical, and preferably quantifiable information most easily satisfies these criteria; therefore, the aspects of traditional knowledge that have these characteristics are most often seen to be valid and useful. Myths, practices, values, beliefs, and other contextual knowledge, however, tend to be discarded, because science has little means of dealing with such subjective, nonpositivist knowledge (Pierotti and Wildcat, 1997). Traditional knowledge that has successfully navigated the scientization process becomes, in the eyes of conventional science and its practitioners, truthful, useful, and ultimately, powerful. This knowledge, however, has also been stripped of the characteristics that make it traditional (Agrawal, 1995; Simpson, 2001).

In the NWT, most provisions for including traditional knowledge in environmental decision making involve "scientized" traditional knowledge (Cizek, 1990; Stevenson, 1996; Zamparo, 1996). Such information typically consists of empirical observations made by elders and other land users that answer who, what, when, and where questions. Land-use and occupancy research, which is the most common forum for introducing traditional knowledge into environmental decision making (Kuhn et al., 1994), reduces traditional knowledge to points or polygons on a map denoting a person's name, an activity, a time period, and a location, data that are easily amenable to scientific manipulation and analysis (Duerden and Kuhn, 1998; Tobias, 2000). The "scientization" of traditional knowledge is also demonstrated in climate-change research (Riedlinger and Berkes, 2001), resource management (Freeman, 1992), and environmental assessment (De Beers Canada Mining Inc., 2002).

Credibility also tends to be given to traditional knowledge when it compares favorably with observations and explanations generated by scientific means (Sillitoe, 1998; Raffles, 2002). Cruikshank (1981) examined the oral traditions of aboriginal peoples in the Yukon, looking for areas of convergence between their legends and known geological data. She discovered concurrence between aboriginal narratives concerning great floods and geological evidence pointing to the existence of ice-dammed lakes in the region, consequently lending credence to the oral traditions. In other cases, science will accept traditional knowledge only if it helps bolster existing and established scientific doctrines (Deloria, 1997). An example is the perceived caribou crisis in the eastern Arctic during the early 1980s. Biologists, on the basis of results from scientific aerial censuses, warned that caribou populations in the region were seriously depleted and overhunted. Inuit land users in the region disputed this contention, asserting that variable seasonal caribou movements had resulted in deficient census results. To resolve the issue, more aerial censuses were conducted, which resulted in a dramatic increase in caribou population estimates (Freeman, 1989). Only then was the traditional knowledge of the Inuit land users acknowledged to be valid.

Conversely, when traditional knowledge is not substantiated by scientific methods, results, and conclusions, it is commonly ignored or discarded (Raffles, 2002). According to Deloria (1997), traditional knowledge not corroborated by scientific evidence is often prematurely rejected instead of being viewed as substance for future inquiry. Orthodox science and traditional knowledge are established in disparate worldviews: science mostly views nature as mechanical and separate from humans, whereas traditional knowledge typically sees humans as part of a spiritual and animistic nature (Martinez, 1994; Berkes, 1998). As a result, the two systems of understanding often have quite distinct explanations for environmental 
phenomena. In NWT environmental decision making, this is evidenced by the common rejection of traditional knowledge that addresses how and why questions.

This point is well illustrated in the following two examples drawn from personal experience. The first example has to do with injured caribou. Aboriginal land users across the NWT noticed a high incidence of limping Bathurst caribou during the summer of 2001. Samples of caribou legs with swollen, lacerated joints were collected by aboriginal hunters and sent to GNWT biologists for scientific analysis. The government scientists concluded that the swollen joints were a natural occurrence, a result of a wet summer that had exacerbated the occurrence of foot rot in the caribou (T. Lockhart, pers. comm. 2001). Aboriginal elders, however, maintained that although they had seen many summers that were far more wet, they had never in their long lives seen such a high incidence of caribou injured in such a fashion ( $\mathrm{KKDFN}$ and Ellis, 2002). The elders attributed these injuries to the large, jagged rocks used to form the sides of mine roads. Caribou, they maintained, injured themselves when they traveled across these roads during their migrations. The GNWT rejected these claims and closed the matter. The elders' viewpoint may indeed have been incorrect, but it certainly warranted further investigation.

The second example is drawn from a technical workshop of the West Kitikmeot Slave Study Society. During a breakout session, aboriginal land users and governmental wildlife biologists discussed the westward shift in muskoxen distribution during past years. Some elders explained that this shift in distribution mirrored a similar shift in the Denésołıné (Chipewyan) people over the past 50 years, and that the muskoxen were following the people because they missed them and wanted their company. This was a conclusion that would never be reached through conventional scientific means, and it completely baffled the participating scientific experts. Ultimately, the scientific experts ignored the elders' interpretation without further dialogue, and proceeded to devise an explanation for the distribution shift using standard principles of population ecology.

Traditional knowledge contributions are commonly rejected in environmental decision-making proceedings because they are deemed anecdotal, and therefore non-replicable and non-universal (Hobson, 1992; Duerden and Kuhn, 1998). Traditional knowledge communications are usually framed in personal experience and take the form of stories. It is perhaps natural to regard them merely as expressions of personal opinion. These stories, however, are meant to convey the cumulative and collective experience of a society (Peat, 1996; Paci et al., 2002). Traditional knowledge experts derive their legitimacy and knowledge from their membership in a lineage intimately tied to a culture and a territory. In effect, these experts (e.g., elders) act as individual manifestations of a culture's collective knowledge and wisdom (Goulet, 1998; Roue and Nakashima, 2002). This is not to say that these experts know everything about their people's traditional knowledge. Rather, what they do know is derived from the broader cultural experience. This message is often lost in environmental governance processes. For example, in the information request period of the Snap Lake Diamond Project environmental assessment, MVEIRB technical consultants questioned the universality and reliability of documented elders' statements in the De Beers environmental assessment report (MVEIRB, 2002). These consultants maintained that the statements were individual opinions of an anecdotal nature, and thus were not real information.

\section{The Appropriation of Traditional Knowledge Research}

The focus of this critique now shifts to traditional knowledge research, an oft-used bottom-up approach. Aboriginal groups devote some of their self-generated funds to support traditional knowledge research. However, as most aboriginal groups have little internal capital and receive typically minimal core funds from a fiduciary, most funding for traditional knowledge research comes from government, industry, and research organizations. Consequently, the objectives of most traditional knowledge research reflect the agendas of outside funding agencies. Research products must be tailored to needs and expectations that, like the agencies themselves, are customarily immersed in Euro-Canadian culture and science (Flaherty, 1995).

Aboriginal groups, when interacting with outside funding agencies, most often do so on terms set, consciously or unconsciously, by the latter (Alcorn, 1993). Research project results must be communicable and useful to funding agencies that are largely rooted in the Euro-Canadian cultural tradition of bureaucratic state management (Nadasdy, 1999). Research results must therefore be transformed into forms understandable to these funding agencies, with emphasis on those aspects of traditional knowledge that are amenable to "scientization" and present solutions to environmental problems.

Consequently, most traditional knowledge research projects require one or more primary researchers in an intermediate role, who can successfully drive the research agenda and ensure that the needs and expectations of both the aboriginal group whose traditional knowledge is being researched and the funding agency are satisfied. Aboriginal cultures do not have a tradition of formal research in the Euro-Canadian sense of the word (Colorado, 1988); thus, aboriginal people with such a research background are rare in the NWT. Accordingly, primary researchers with an intermediate role in traditional knowledge projects are almost invariably Euro-Canadians, educated in the scientific tradition, who have an interest in traditional knowledge and aboriginal people (Simpson, 2001). Examples to support this assertion abound in northern Canada. Euro-Canadian researchers fulfil roles as primary researchers in the Tuktu and Nogak Project with the Inuit of the 
Coronation Gulf (WKSS, 2001), the Whaehdoo Naowoo Program with the Dogrib (Barnaby et al., 2003a), and various research initiatives with the communities of Deliné and Łutsël K'é.

Primary researchers usually devise overall research plans based on questions postulated by aboriginal communities or authorities and are responsible for research theory and design. They ensure timely and satisfactory completion of research products in a form intelligible to funding agencies (reports, maps, etc.). They also train aboriginal researchers in theory and methods and generally carry out activities that build capacity in conducting formal research (Zamparo, 1996; WKSS, 2001). Aboriginal researchers in traditional knowledge projects typically assist and learn from the primary researcher. They are usually involved in day-to-day tasks such as information gathering, organization, database entry, and community reporting under the supervision of the primary researcher. However, they often play a limited role in the analysis, interpretation, and publication of research results (E. Marlowe, pers. comm. 2002).

Because of these circumstances, non-aboriginal researchers often become point people for traditional knowledge research projects. Despite the best efforts of many non-aboriginal researchers to ensure that due credit is given to aboriginal researchers and communities, they find the role of "expert" is often foisted upon them by EuroCanadian society. These researchers tend to receive much of the credit for research conducted in aboriginal communities, as they are the primary creators of the reports, presentations, and publications that mean something to Western institutions and science (Raffles, 2002). Academic ownership of research thus often falls, willingly or not, into the hands of non-aboriginal researchers. The aboriginal researchers and the people whose knowledge is being researched in the first place are commonly seen to have only a supportive role (St. Denis, 1992). As an end result, traditional knowledge becomes separated from the people who are its holders and practitioners (Simpson, 2001), and non-aboriginal researchers, now acknowledged as "experts," gain a measure of ownership over an aboriginal group's traditional knowledge (Flaherty, 1995; Nadasdy, 1999).

\section{Capacity Building}

Despite the appropriation of traditional knowledge, traditional knowledge research has had some success in empowering aboriginal people. Aboriginal researchers are most typically younger to middle-aged individuals who have been educated to a varying degree in both traditional and Western ways. They usually can speak their native language, have some familiarity with traditional skills and practices, and are somewhat proficient in formal research skills such as writing, typing, and information management (Colorado, 1988; Tobias, 2000; WKSS, 2001). Quite often a non-aboriginal researcher trains these individuals in scientific research methods. As well, they are educated in traditional knowledge through their interactions with elders and other land users. The research activities in which they are involved provide an inter-generational conduit for the transmission of traditional knowledge (ICC, 1996). This balanced training is essential, as these researchers must interact with elders and land users, often on the land, in order to gather traditional knowledge. The knowledge they gather must then be manipulated and converted into a format understandable to the agencies that provide funding and use research results in environmental management (Nadasdy, 1999). Aboriginal researchers increase their facility with traditional and scientific principles, practices, and knowledge, and in a sense become empowered.

As an example, a traditional knowledge research project has been ongoing in Lutsël K'é for four years, with financial support from industry. Two young aboriginal people have been creating a traditional knowledge database. The purpose of this database is to store and make accessible traditional land-use information and oral histories. Both researchers have been trained in database and Geographic Information System software, as well as information management methods. They have also learned a great deal about their heritage and their traditional knowledge through regular, research-related interaction with elders and other land users. Through an increase in knowledge, they have augmented their capacity (J. Lockhart, pers. comm. 2004).

\section{DISCUSSION}

In the end, have strategies used to bring traditional knowledge into environmental decision making been effective? Strategies used to foster traditional knowledge at the community level have had some success. At a bare minimum, both top-down and bottom-up strategies have provided some gainful employment for aboriginal people (e.g., in traditional knowledge research). At best, aboriginal people are learning and maintaining the traditional knowledge and practices of their people, especially when the usual channels whereby traditional knowledge is transmitted have broken down. Through education, aboriginal people are becoming empowered.

However, often this empowerment occurs in the broader context of the needs and expectations of Euro-Canadian agencies and their decision-making processes. While policies advocate that traditional knowledge and governance structures include aboriginal participation, true power remains concentrated in Euro-Canadian bureaucratic structures, and Euro-Canadian values remain the primary basis for action. Aboriginal people and their knowledge are often empowered only to the degree to which they conform to these structures and values. Traditional knowledge is often researched only insofar as it is useful to Westernstyle environmental governance, and it has become another field of academic expertise (Flaherty, 1995). All too 
often, aboriginal people are becoming empowered not upon their own terms, but largely upon terms set by EuroCanadian society.

Strategies for fostering the influence of traditional knowledge in environmental decision making have not had any significant degree of success. Upon being brought into decision-making processes, traditional knowledge is commonly ignored, misunderstood, or transformed into something palatable to conventional environmental governance. Current practice essentially changes traditional knowledge into science. At the same time, the values and practices associated with traditional knowledge are commonly discarded or ignored because they are incompatible with science and dominant Euro-Canadian values. It is, however, these very values and practices that can serve to help realize environmental decision making that focuses upon environmental stewardship and respect for the land (Paci et al., 2002). Traditional beliefs, values, and practices can help foster sustainable relationships between humans and nature. However, these beliefs, values, and practices must first be accepted as a valid basis for decision making. This is not to say that traditional knowledge contributions should be accepted and incorporated into environmental decision making without question. Rather, they should be considered upon their own terms as valid substance for discussion and debate, arising as they do from an independently viable system of knowledge and ultimately, from a unique way of life.

\section{The Politics of Traditional Knowledge}

There may be an underlying political reason why strategies for fostering traditional knowledge in environmental decision making have often been unsuccessful in the NWT. Simply stated, advocacy of traditional knowledge threatens the stability of conventional power structures rooted in the Western industrial complex. The driving force behind this complex is growth and, consequently, industrial development. Science, employed as a tool by the industrial complex, arose from, and is embedded in, the values of European industrial culture (Gamble, 1986; St. Denis, 1992; Roots, 1998), as are the structures and procedures of environmental governance in the NWT (Stevenson, 1996; Usher, 2000). Traditional knowledge often challenges the values and beliefs of the Euro-Canadian industrial complex, as well as the institutions that uphold them. To empower traditional knowledge and its aboriginal holders on their own terms necessarily means to give voice to a system of understanding that may oppose the objectives and practices of Euro-Canadian institutions. Thus, beneath a veneer of "best of intentions," traditional knowledge policies and initiatives have often served to limit the real empowerment of traditional knowledge and its aboriginal holders via integration into the Euro-Canadian cultural context (Nadasdy, 1999; Huntington, 2000). Traditional knowledge becomes transformed into a supplementary body of information that, stripped of value, can be integrated into environmental decision making without threatening the foundations of a fundamentally EuroCanadian system (Nadasdy, 1999; Raffles, 2002). The conventional paradigm of environmental decision making thus remains intact and unchallenged.

The problem is partly one of very different and seemingly incompatible systems of understanding, and fundamentally one of power. Even with the very best of intentions to understand traditional knowledge, agents of the dominant Euro-Canadian society are unavoidably enmeshed in their own cultural values, practices, and institutions. Mechanisms to bring traditional knowledge into the realm of environmental decision making are couched in these cultural artifacts. Initiatives to incorporate traditional knowledge into environmental decision making can be effective only if they strive to address this problem by adapting conventional environmental decision making to aboriginal ways of knowing and doing, rather than the conventional converse.

There must be a shift in the balance of power, a reformulation of the values, practices, and knowledge that underlie environmental decision-making processes. Power over land-based knowledge and the consequent power over land must be asserted by aboriginal peoples, taken out of the exclusive realm of science and Euro-Canadian institutions, and taken into a realm where traditional ways of knowing and doing share equal influence.

\section{REFERENCES}

AGRAWAL, A. 1995. Dismantling the divide between indigenous and scientific knowledge. Development and Change 26(3): $413-440$.

2002. Indigenous knowledge and the politics of classification. International Social Science Journal 54(173): 287-297.

ALCORN, J.B. 1993. Indigenous peoples and conservation. Conservation Biology 7(2):424-426.

ANTOINE, J. 2002. Update on traditional economy. Statement to the Northwest Territories Legislative Assembly, 24 June 2002. www.horizons.gov.nt.ca/Thisweek/minspeech.asp. Accessed January 2005.

BARNABY, J., EMERY, A., and LEGAT, A. 2003a. Traditional knowledge interpreters: Project Advisory Committee terms of reference. Unpubl. document available from Joanne Barnaby, Box 3086, Hay River Reserve, Northwest Territories X0E 1G4. . 2003b. Needs assessment study to identify the knowledge and skills required to fully utilize the strengths of traditional knowledge and Western science in the management of northern resources. Final report submitted to Indian and Northern Affairs Canada. Unpubl. document available from Joanne Barnaby, Box 3086, Hay River Reserve, Northwest Territories X0E 1 G4.

BERKES, F. 1998. The nature of traditional ecological knowledge and the Canada-wide experience. Terra Borealis 1:1-3.

BERKES, F., COLDING, J., and FOLKE, C. 2000. Rediscovery of traditional ecological knowledge as adaptive management. Ecological Applications 10(5):1251-1262. 
BHPB (BHP BILLITON DIAMONDS INC). 2001. Environmental agreement annual report 2001 - Plain English summary. Yellowknife: BHP Billiton Diamonds Inc.

BIELAWSKI, E. 2003. Rogue diamonds. Vancouver: Douglas and McIntyre.

BLONDIN, G. 1990. When the world was new: Stories from the Sahtu Dene. Yellowknife: Outcrop, the Northern Publishers.

CIZEK, P. 1990. The Beverly-Kaminuriak caribou management board: A case study of aboriginal participation in resource management. Background Paper \#1. Ottawa: Canadian Arctic Resources Committee.

COLORADO, P. 1988. Bridging native and western science. Convergence 21(2-3):49-67.

CRUIKSHANK, J. 1981. Legend and landscape: Convergence of oral and scientific traditions in the Yukon Territory. Arctic Anthropology 28(2):67-90.

DDMI (DIAVIK DIAMOND MINES INC.). 2001. The Environmental Monitoring Advisory Board for Diavik Diamond Mine becomes operational. www.diavik.ca/News/2001/ body_ema b.html. Accessed 30 March 2003.

DE BEERS CANADA MINING INC. 2002. Snap Lake Diamond Project environmental assessment report. 3 vols. Yellowknife: De Beers Canada Mining Inc.

DELORIA, V., Jr. 1997. Red earth, white lies: Native Americans and the myth of scientific fact. Golden, Colorado: Fulcrum Publishing.

DOGRIB TREATY 11 COUNCIL. 2001. Caribou migration and the state of their habitat. Final report submitted to the West Kitikmeot/Slave Study Society. www.wkss.nt.ca/HTML/ 08_ProjectsReports/PDF/CaribouMigrationFinal.pdf. Accessed January 2005.

DUERDEN, F., and KUHN, R.G. 1998. Scale, context and application of traditional knowledge of the Canadian North. Polar Record 34(188):31-38.

FLAHERTY, M. 1995. Freedom of expression or freedom of exploitation. Northern Review 14:178-185.

FREEMAN, M.M.R. 1976. Inuit Land-Use and Occupancy Project. 3 vols. Ottawa: Department of Indian and Northern Affairs.

- 1989. Graphs and gaffs: A cautionary tale in the common property resource debate. In: Berkes, F., ed. Common property resources: Ecology and community-based sustainable development. New York: Belhaven Press. 92-109.

. 1992. The nature and utility of traditional ecological knowledge. Northern Perspectives 20(1):1-5.

GAMBLE, D. 1986. Crushing of cultures: Western applied science in northern societies. Arctic 39(1):20-23.

GNWT (GOVERNMENT OF THE NORTHWEST TERRITORIES). 1993. Policy 52.06 - Traditional Knowledge. www.gov.nt.ca/RWED/plc/pdf/5206.pdf. Accessed January 2005.

- 2003. Community Meetings. www.nwtwildlife. rwed.gov.nt.ca/Research\%20Permits/Default.htm. Accessed March 30, 2003.

GOULET, J.A. 1998. Ways of knowing: Experience, knowledge and power among the Dene Tha. Vancouver: UBC Press.

GUNN, A., ARLOOKTOO, G., and KAOMAYOK, D. 1988. The contribution of the ecological knowledge of Inuit to wildlife management in the Northwest Territories. In: Freeman, M.M.R., and Carbyn, L.N., eds. Traditional knowledge and renewable resource management in northern regions. Edmonton: Boreal Institute for Northern Studies.

GWICH' IN ELDERS and RAYGORODETSKY, G. 1997. Nành' kak geenjit Gwich'in ginjik; Gwich'in words about the land. Inuvik: Gwich'in Renewable Resource Board.

HOBSON, G. 1992. Traditional knowledge is science. Northern Perspectives 20(1):2.

HUNTINGTON, H.P. 1998. Observations on the utility of the semi-directed interview for documenting traditional ecological knowledge. Arctic 51(3):237-242.

- 2000. Using traditional ecological knowledge in science: Methods and applications. Ecological Applications 10(5): 1270-1274.

ICC (INUIT CIRCUMPOLAR CONFERENCE). 1996. Recommendations on the integration of two ways of knowing: Traditional indigenous knowledge and scientific knowledge. Seminar on the documentation and application of indigenous knowledge, 15-17 November 1996, Inuvik, NWT, Canada. Available from ICC, 170 Laurier Avenue West, Suite 504, Ottawa, Ontario K1P 5V5.

IEMA (INDEPENDENT ENVIRONMENT MONITORING AGENCY). 2001. 2000-2001 annual report - plain English summary. Yellowknife: IEMA.

INAC (INDIAN AND NORTHERN AFFAIRS CANADA). 2003. INAC's principles of sustainable development. www.aincinac.gc.ca/sd/princ_e.html. Accessed December 2004.

KRUSE, J., KLEIN, D., BRAUND, S., MOOREHEAD, L., and SIMEONE, B. 1998. Co-management of natural resources: A comparison of two caribou management systems. Human Organization 47(4):447-458.

KUHN, R.G., DUERDEN, F., and CLYDE, K. 1994. Government agencies and the utilization of indigenous land use information in the Yukon. Environments 22(3):76-83.

LEGAT, A., ed. 1991. Report of the Traditional Knowledge Working Group. Yellowknife: Department of Culture and Communications, Government of the Northwest Territories.

ŁKDFN (ŁUTSËL K'É DENE FIRST NATION), and ELLIS, S. 2002. Traditional knowledge in the Na Yaghe Kue study region: An assessment of the Snap Lake Project. In: Snap Lake Diamond Project environmental assessment report. Vol. 3, Appendix IV.3. Yellowknife: De Beers Canada Mining Inc.

2002. Traditional knowledge in the Kache Tué study region: Phase three - towards a comprehensive environmental monitoring plan in the Kakinene region. Final Report Submitted to the West Kitikmeot/Slave Study Society. www.wkss.nt.ca/ HTML/08_ProjectsReports/PDF/TradEcoKacheTueFinal 2002.pdf. Accessed January 2005.

ŁKDFN (ŁUTSËL K'É DENE FIRST NATION), PARLEE, B., BASIL, M., and CASAWAY, N. 2001. Traditional ecological knowledge in the Kaché Tué study region. Final report submitted to the West Kitikmeot/Slave Study Society. www.wkss.nt.ca/ HTML/08_ProjectsReports/PDF/TradEcoKacheTueFinal.pdf. Accessed January 2005.

MARTINEZ, D. 1994. Traditional environmental knowledge connects land and culture. Winds of Change 9(4):89-94. 
MAURO, F., and HARDISON, P.D. 2000. Traditional knowledge of indigenous and local communities: International debate and policy initiatives. Ecological Applications 10(5):1263-1269.

MVEIRB (MACKENZIE VALLEY ENVIRONMENTAL IMPACT REVIEW BOARD). 2002. Information requests of the De Beers Canada Mining Inc. Snap Lake Diamond Project. Unpubl. document available from the MVEIRB, Box 938, 200 Scotia Centre, 5102 - 50th Avenue, Yellowknife, Northwest Territories X1A 2 N7.

- 2003. Local government and the MVRMA. Www. mveirb.nt.ca/HTML/MVEA/localgov.asp. Accessed March 30, 2003.

2004. Rules of procedure for environmental assessment and environmental impact review proceedings. www.mveirb. nt.ca/HTML/MVGuides/MVEIRB_Rules_of_Procedure _0411.pdf. Accessed January 2005.

MVLWB (MACKENZIE VALLEY LAND AND WATER BOARD). 2002. Transcripts of the public hearing for BHP Billiton Expansion. Available from MVLWB, PO Box 2130, 7th Floor, 4910 - 50th Avenue, Yellowknife, Northwest Territories X1A 2 P6.

NADASDY, P. 1999. The politics of TEK: Power and the "integration" of knowledge. Arctic Anthropology 36(1-2): $1-18$.

PACI, C., TOBIN, A., and ROBB, P. 2002. Reconsidering the Canadian Environmental Impact Assessment Act: A place for traditional environmental knowledge. Environmental Impact Assessment Review 22:111-127.

PEAT, D.F. 1996. I have a map in my head. ReVision 18(3):11 - 16.

PETITOT, E. 1976. The book of Dene. Yellowknife: Program Development Division, Department of Education.

PIEROTTI, R., and WILDCAT, D. 1997. Native tradition, evolution and creation. Winds of Change 12(2):70-73.

PURCELL, T., and ONJORO, E.A. 2002. Indigenous knowledge, power and parity: Models of knowledge integration. In: Sillitoe, P., Bicker, A., and Pottier, J., eds. Participating in development: Approaches to indigenous knowledge. New York: Routledge. $162-188$.

RAFFLES, H. 2002. Intimate knowledge. International Social Science Journal 54(173):325-335.
RIEDLINGER, D., and BERKES, F. 2001. Contributions of traditional knowledge to understanding climate change in the Canadian Arctic. Polar Record 37(203):315-328.

ROOTS, F. 1998. Inclusion of different knowledge systems in research. Terra Borealis 1:42-49.

ROUE, M., and NAKASHIMA, D. 2002. Knowledge and foresight: The predictive capacity of traditional knowledge applied to environmental assessment. International Social Science Journal 54(173):337-347.

SILLITOE, P. 1998. The development of traditional knowledge: A new applied anthropology. Current Anthropology 39(2): $223-252$.

SIMPSON, L. 2001. Aboriginal peoples and knowledge: Decolonizing our processes. Canadian Journal of Native Studies 21(1):137-148.

SNOWSHOE, C. 1977. A trapper's life. In: Watkins, M., ed. Dene Nation: The colony within. Toronto: University of Toronto Press. 28-31.

ST. DENIS, V. 1992. Community-based participatory research: Aspects of the concept relevant for practice. Native Studies Review 8(2):51-74.

STEVENSON, M. 1996. Indigenous knowledge in environmental assessment. Arctic 49(3):278-291.

TEED, T. 2002. This land is really the land of Drygeese. Yellowknife: NWT Treaty \#8 Tribal Corporation.

TOBIAS, T.N. 2000. Chief Kerry's moose: A guidebook to landuse and occupancy mapping, research design and data collection. Vancouver: Union of BC Indian Chiefs and Ecotrust Canada.

USHER, P.J. 1987. Indigenous management systems and the conservation of wildlife in the Canadian North. Alternatives 14(1):3-9.

. 2000. Traditional ecological knowledge in environmental assessment and management. Arctic 53(2):183-193.

WILES, A., McEWEN, J., and SADAR, M.H. 1999. Use of traditional ecological knowledge in environmental assessment of uranium mining in the Athabasca Saskatchewan. Impact Assessment and Project Appraisal 18(2):107-114.

WKSS (West Kitikmeot/Slave Study Society). 2001. Final report of the West Kitikmeot Slave Study. Yellowknife: West Kitikmeot/ Slave Study Society.

ZAMPARO, J. 1996. Informing the fact: Inuit traditional knowledge contributes another perspective. Geoscience Canada 23(4): $261-266$. 